\title{
Article \\ Novel Four-Cell Lenticular Honeycomb Deployable Boom with Enhanced Stiffness
}

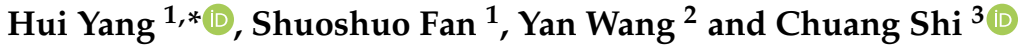 \\ 1 College of Electrical Engineering and Automation, Anhui University, Hefei 230601, China; \\ f876272482@163.com \\ 2 College of Mechanical Engineering, Yanshan University, Qinhuangdao 066004, China; wangyan_597@163.com \\ 3 State Key Laboratory of Robotics and System, Harbin Institute of Technology, Harbin 150001, China; \\ ty12shichuang@126.com \\ * Correspondence: huiyang_0431@163.com
}

Citation: Yang, H.; Fan, S.; Wang, Y.; Shi, C. Novel Four-Cell Lenticular

Honeycomb Deployable Boom with Enhanced Stiffness. Materials 2022, 15, 306. https://doi.org/10.3390/ ma15010306

Academic Editor: Enrique Casarejos

Received: 10 November 2021

Accepted: 29 December 2021

Published: 1 January 2022

Publisher's Note: MDPI stays neutral with regard to jurisdictional claims in published maps and institutional affiliations.

Copyright: (c) 2022 by the authors. Licensee MDPI, Basel, Switzerland. This article is an open access article distributed under the terms and conditions of the Creative Commons Attribution (CC BY) license (https:// creativecommons.org/licenses/by/ $4.0 /)$.

\begin{abstract}
Composite thin-walled booms can easily be folded and self-deployed by releasing stored strain energy. Thus, such booms can be used to deploy antennas, solar sails, and optical telescopes. In the present work, a new four-cell lenticular honeycomb deployable (FLHD) boom is proposed, and the relevant parameters are optimized. Coiling dynamics analysis of the FLHD boom under a pure bending load is performed using nonlinear explicit dynamics analysis, and the coiling simulation is divided into three consecutive steps, namely, the flattening step, the holding step, and the hub coiling step. An optimal design method for the coiling of the FLHD boom is developed based on a back propagation neural network (BPNN). A full factorial design of the experimental method is applied to create 36 sample points, and surrogate models of the coiling peak moment $\left(M_{\text {peak }}\right)$ and maximum principal stress $\left(S_{\max }\right)$ are established using the BPNN. Fatigue cracks caused by stress concentration are avoided by setting $S_{\max }$ to a specific constraint and the wrapping $M_{\text {peak }}$ and mass of the FLHD boom as objectives. Non-dominated sorting genetic algorithm-II is used for optimization via ISIGHT software.
\end{abstract}

Keywords: deployable structures; four-cell lenticular honeycomb boom; coiling dynamics; optimization; composite material

\section{Introduction}

Deployable composite ultra-thin booms can easily be folded and self-deployed by releasing stored strain energy; thus, these booms can be applied to membrane antennas and solar sails. Many cross-sectional deployable booms, such as lenticular booms [1], triangular rollable and collapsible (TRAC) booms [2,3], and storable tubular extendable member (STEM) booms [4,5], are available.

For example, a novel collapsible boom has been applied to a roll-out solar array, and rolling and deploying experiments have been performed on this prototype [6]. Coiling of the tape-spring and composite thin-walled booms $[7,8]$ and the micromechanical behavior of two-ply weave laminates under small strains have also been investigated [9]. An active-passive composited driving deployable lenticular boom for space probes has been proposed. In addition, an optimal design of lenticular booms has been developed for its modal and wrapping analysis [10-12]. Experiments and numerical studies of the flattening and wrapping processes of deployable composite thin-walled lenticular tubes have been conducted [13-17]. A TRAC boom has been designed using a data-driven computational framework without considering the influence of the bonding web between two tapesprings $[18,19]$. The shapes of the consistent features of folded orthotropic collapsible booms made from metal and woven laminated composites have been calculated [20]. TRAC booms feature 10-fold greater cross-sectional inertia compared with lenticular booms and 34-fold greater cross-sectional inertia compared with STEM booms at the same package 
height [21]. An N-shaped cross-section boom has been proposed, and its post-buckling properties have been optimized [22].

A four-cell lenticular honeycomb deployable (FLHD) boom composed of four pairwise symmetrical tape-springs has been proposed, as shown in Figure 1. Here, the two outer tape-springs feature only two bonded webs and four arcs, while the two inner tape-springs have four bonded webs and eight outer tangent arcs. The FLHD boom illustrated in Figure $1 \mathrm{c}$ is derived from the modified double lenticular (MDL) boom shown in Figure 1b. Compared with the DL boom in Figure 1a, the middle segment of the MDL boom is a smooth section located at the junction of the two arc segments. This segment is also key to the expansion of the MDL boom into the FLHD boom.

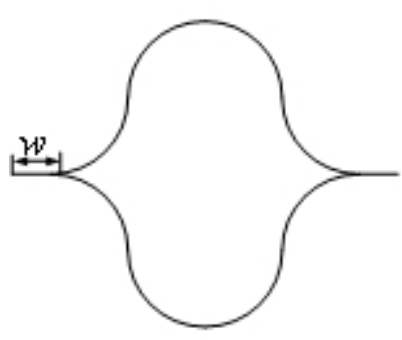

(a) DL boom

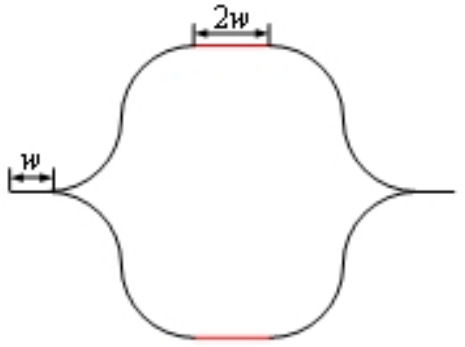

(b) MDL boom

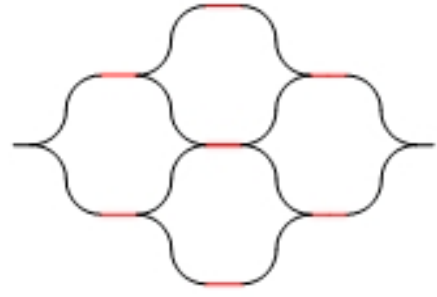

(c) FLHD boom

Figure 1. Three kinds of composite deployable booms.

The FLHD boom has higher bending and torsional stiffness than the DL and TRAC booms. However, material damage may occur during the dynamic process of complete coiling around the hub. Thus, geometric parameters critical to the deployment mechanism of the FLHD boom should be optimized.

When the FLHD boom is close to the holding state after the full-flattening step, its cross-section could abruptly snap. The deformation is located in a short transverse curved region, and the moment increases quickly and reaches a peak moment (Mpeak). Mpeak and mass are set as objectives, while the maximum principal stress (Smax) is set as a constraint to increase the deployment-state stiffness. The bonded web- $1(\mathrm{w})$, arc radius ( $\mathrm{r}$ ), and central angle $(\theta)$ of the tape-spring are set as variables. The finite element (FE) models of the full-coiling process are solved using the ABAQUS/Explicit solver. Non-dominated sorting genetic algorithm-II (NSGA-II) is used to obtain an optimal design.

The contents of this manuscript are as follows. The behavior of the FLHD boom is presented in Section 2.1, the three analysis steps of the complete coiling process are presented in Section 2.2, and the numerical results are discussed in Section 2.3. Surrogate models are established using a back propagation neural network (BPNN) in Sections 3 and 4 . The multi-objective optimization design is presented in Section 5. Concluding remarks are provided in Section 6.

\section{Problem Description}

\subsection{Behavior of FLHD Booms}

The geometric dimensions of the cross-section of an FLHD boom are shown in Figure 2. The FLHD boom is similar to the lenticular boom: it can be flattened and coiled and then expanded to its initial state by releasing stored strain energy. The FLHD boom is composed of four sets of two symmetrical tape-springs and has three independent parameters, i.e., the central angle $\theta$, the arc radius $r$, and the bonded web- 1 width $w$. The mass of the FLHD boom is written as:

$$
\operatorname{mass}(h, \theta, r)=8 \rho \cdot L \cdot t(3 r \theta+w)
$$

where $t$ is the thickness of the thin-walled boom. 


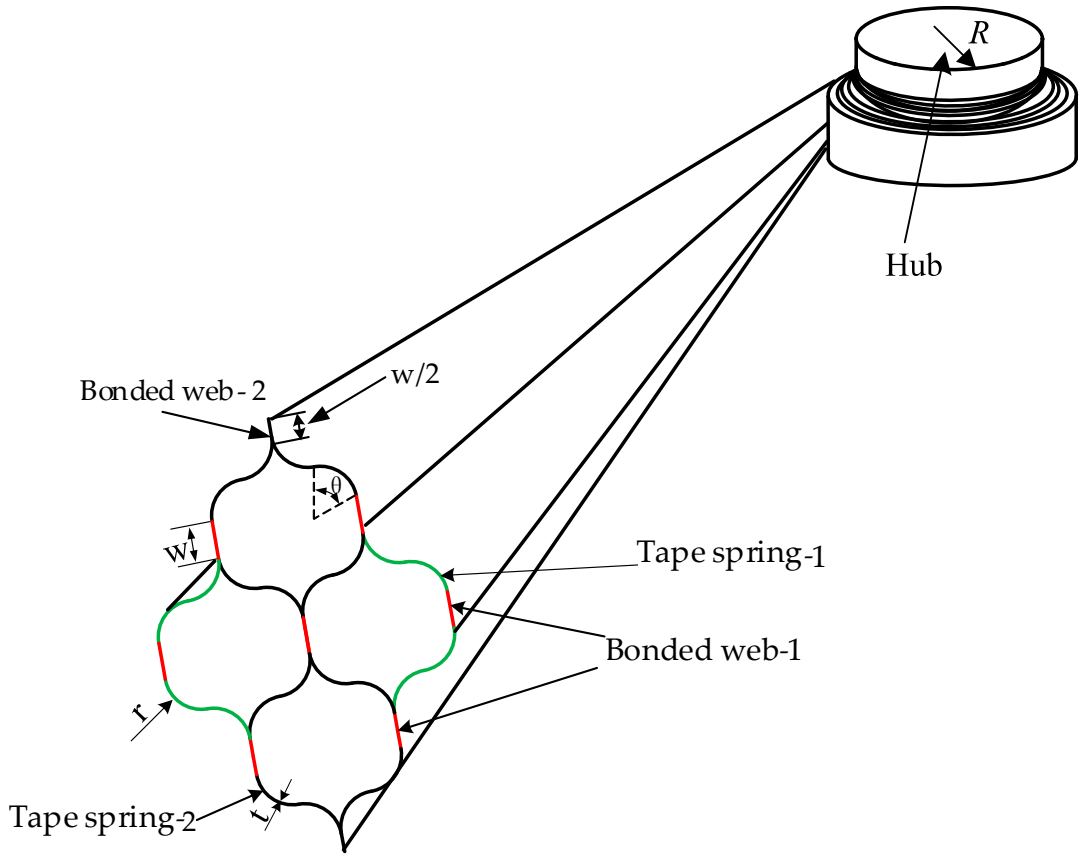

Figure 2. Geometric dimensions of the cross-section of the FLHD boom.

The FLHD boom coiling mechanism is simplified to 15 parts, as shown in Figure 3. Two radial rollers are symmetrically positioned on both sides of the FLHD boom, and 11 circumferential rollers are evenly distributed around a hub. The radius $R$ of the hub is $125 \mathrm{~mm}$, and the radial and circumferential rollers guide the FLHD boom to coil smoothly around the hub. The axial distance between reference point (RP) 13 and RP14 is $78 \mathrm{~mm}$, and the radial distance between the outer arc of the circumferential roller and the edge of the hub is $25 \mathrm{~mm}$. The longitudinal length $(L)$ and $t$ of the FLHD boom are set to $2000 \mathrm{~mm}$ and $0.18 \mathrm{~mm}$, respectively; the stacking sequence of the composite material is $\left[45^{\circ} /-45^{\circ} /-45 /{ }^{\circ} 45^{\circ}\right]$, as shown in Figure 4 , and the thickness of each ply is $t_{p}=0.045 \mathrm{~mm}$. The ply material is T800; it is a strategic new material with low density, good rigidity, and high composite strength, which plays an irreplaceable role in aerospace and other fields. The material properties of T800 are listed in Table 1.

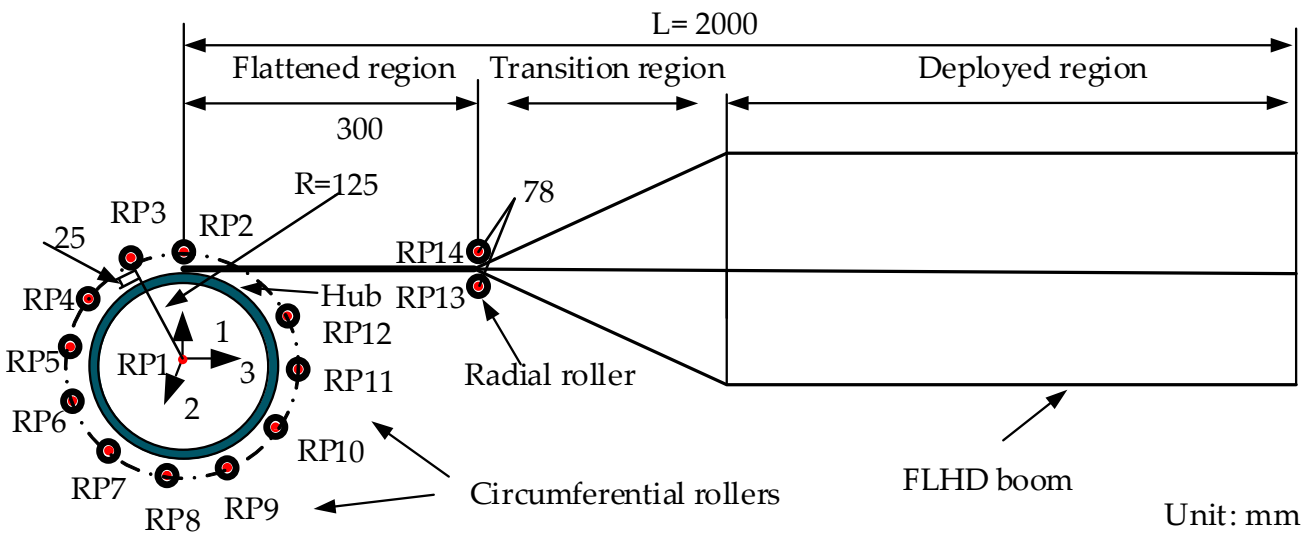

Figure 3. Simplified schematic of the FLHD boom coiling structure. 


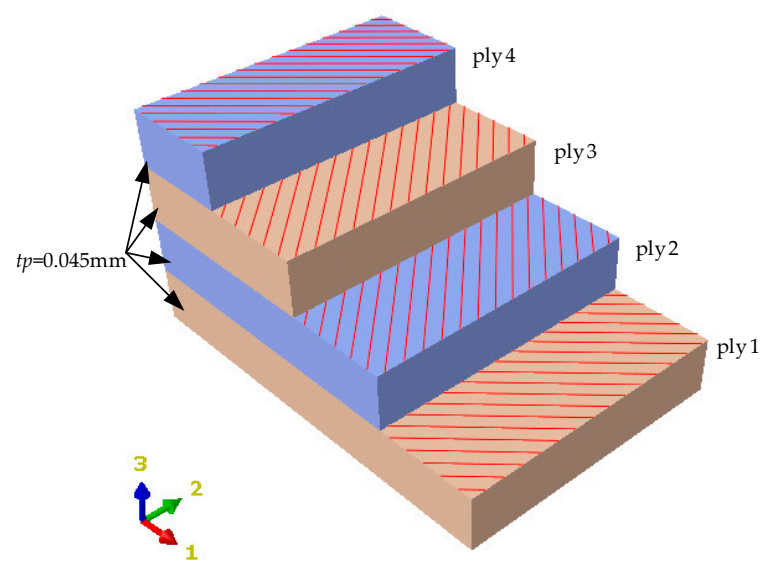

Figure 4. Ply angle diagram of the FLHD boom.

Table 1. Material properties of T800.

\begin{tabular}{cc}
\hline Material Properties & T800 \\
\hline Longitudinal stiffness $E_{1} / \mathrm{GPa}$ & 150 \\
Transverse stiffness $E_{2}=E_{3} / \mathrm{GPa}$ & 9.4 \\
Shear stiffness $G_{12}=G_{13} / \mathrm{GPa}$ & 9.4 \\
In-plane shear stiffness $G_{23} / \mathrm{GPa}$ & 4.5 \\
Poisson's ratio $v$ & 0.3 \\
Density $\rho \mathrm{kg} / \mathrm{m}^{3}$ & 2500 \\
\hline
\end{tabular}

\subsection{Analysis Steps}

An FE model of the FLHD boom is established for numerical analysis. The FLHD boom is defined as an extruded shell consisting of 20,114 nodes and 19,214 four-node reduced integrated shell elements (S4R). The FE model is shown in Figure 5. The outer surface of the hub is connected to control point reference point 1 (RP1), and two FLHD boom nodes at the end of the bonded web are set as slave nodes. All the outer surfaces of the 11 circumferential and 2 radial rollers are connected to reference points from RP2 to RP14. The connections between the bonded web and four tape springs are modeled by the tie constraint. The interactions between the rollers and FLHD boom or between the hub and FLHD boom are constructed with surface contact as a frictionless property. The FLHD boom is divided into segments of $50 \mathrm{~mm}$ and $175 \mathrm{~mm}$ from the left end along the 3-axis. The coiling process consists of a flattening step (step time $0.1 \mathrm{~s}$ ), a holding step (step time $0.05 \mathrm{~s}$ ), and a hub coiling step (step time $0.5 \mathrm{~s}$ ). No direct contact exists between the surface of the boom and the surface of the hub, and an interval of $0.36 \mathrm{~mm}$ is set to avoid stress concentration. The node sets of the FE model are shown in Figure 6.

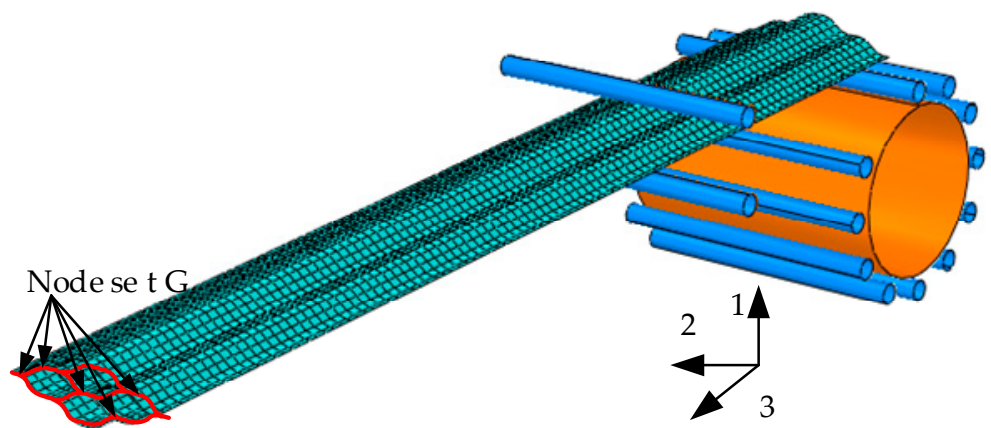

Figure 5. FE model. 


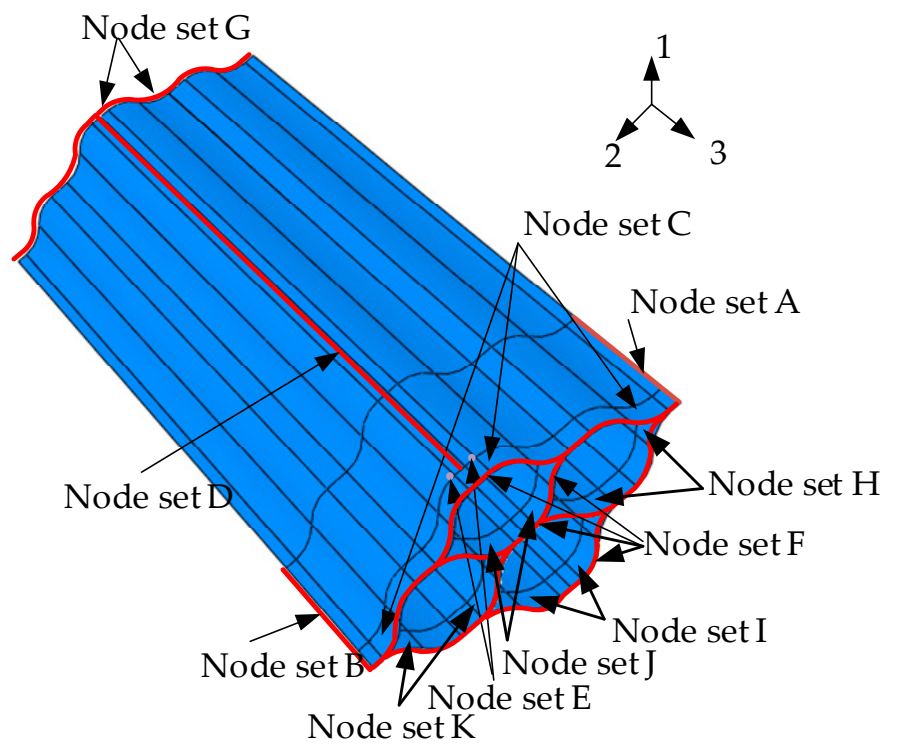

Figure 6. Node sets used in the FE model.

In the first step of the simulation, the FLHD boom is pulled flat using tension. A shell edge load of $800 \mathrm{~N} / \mathrm{m}$ is applied to node-set A along the 2-axis direction, and a shell edge load in the opposite direction with the same size is applied to the B set. A viscous pressure of $0.5 \mathrm{~Pa}$ is applied to all surfaces of the boom to ensure the convergence of the explicit dynamic process. Two $50 \mathrm{~N} / \mathrm{m}$ shell edge loads in opposite directions are applied to node sets $F$ and $G$ along the 3-axis to prevent the FLHD boom from warping. Node-set D and 14 reference points are clamped to fix the FLHD boom, hub, and rollers. The boundary condition of node-set D has fixed; node-sets $\mathrm{A}$ and $\mathrm{B}$ release displacement DoFs along the 1-axis and 2-axis.

In the second step, a pressure of $0.1 \mathrm{MPa}$ is applied to node sets $\mathrm{C}, \mathrm{J}, \mathrm{I}, \mathrm{H}$, and $\mathrm{K}$, and the FLHD boom end is clamped and fixed on the hub. Boundary conditions are set as same as those in the first step.

The last step is coiling one circle around the hub. The connection between the FLHD boom and hub is modeled by a beam-type multi-point constraint. RP1 of the hub is the control point, and node-set $\mathrm{E}$ is considered the salve node. A continuous rotation of $0.5 \mathrm{~s}$ is applied to RP1, the rotation displacement of UR 2 is set to $5.88 \mathrm{rad}$, and a steady step amplitude is established to reduce the loading shock on the FLHD boom. The timestep of the analysis is set to $0.1 \mathrm{~s}$, and other degrees of freedom (DoFs) associated with RP1 are fixed. The DoF of node-set $G$ is also fixed, except for the displacement along the 3-axis. Node-set $G$ release displacement DoFs along the 3-axis. Node-set D releases displacement DoFs along the 1-axis and 3-axis, and rotate DoFs about the 2-axis.

\subsection{Numerical Results and Discussion}

The total CPU time required by an Intel(R) Core(TM) i5-9400F CPU @ 2.90GHz desktop computer to achieve one complete coil is approximately $20 \mathrm{~h}$. The stress nephogram of the flattening, holding, and coiling processes for an FDLH with $\theta=52.5^{\circ}, w=8 \mathrm{~mm}$, and $r=27 \mathrm{~mm}$ is shown in Figure 7 . In the flattening step, $S_{\max }$ is located close to the lower smooth section of the end of the FLHD boom, as shown in Figure 7a; however, in the holding and hub coiling steps, $S_{\max }$ is located in the middle smooth section connected to the arc sections on both sides of the boom near the hub. $S_{\text {max }}$ does not show a regular trend with increasing wrapping angle, and its change shows strong nonlinearity. $S_{\text {max }}$ during the coiling process is $632 \mathrm{MPa}$. If $S_{\max }$ exceeds the allowable stress of the material, the FLHD boom is destroyed. Therefore, $S_{\max }$ should be reduced. RP1 is the geometric center point of the hub, and the change of moment of RP1 during the whole coiling process can best reflect the change of moment of the whole boom. The moment curve of RP1 during the whole 
process is shown in Figure 8. At the beginning of the holding step, the moment increases to a peak of $30.03 \mathrm{Nm}$; it then decreases sharply and reaches a stable value of approximately $5 \mathrm{Nm}$. While the wrapping $M_{\text {peak }}$ can lock the deployment mechanism, if the $M_{\text {peak }}$ is too large, the strain energy of the FLDH boom becomes excessive. Therefore, the coiling $M_{\text {peak }}$ is set as the threshold.

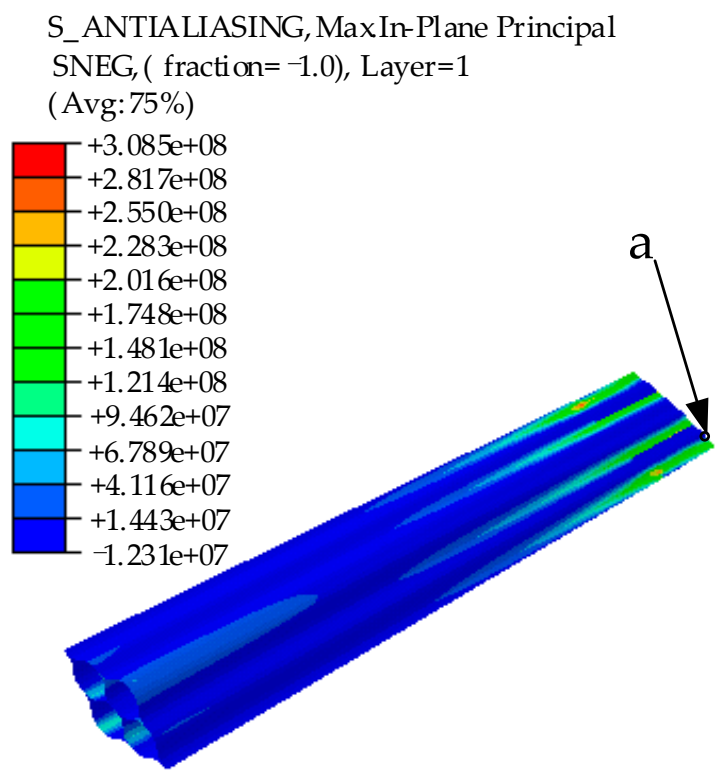

(a) flattening

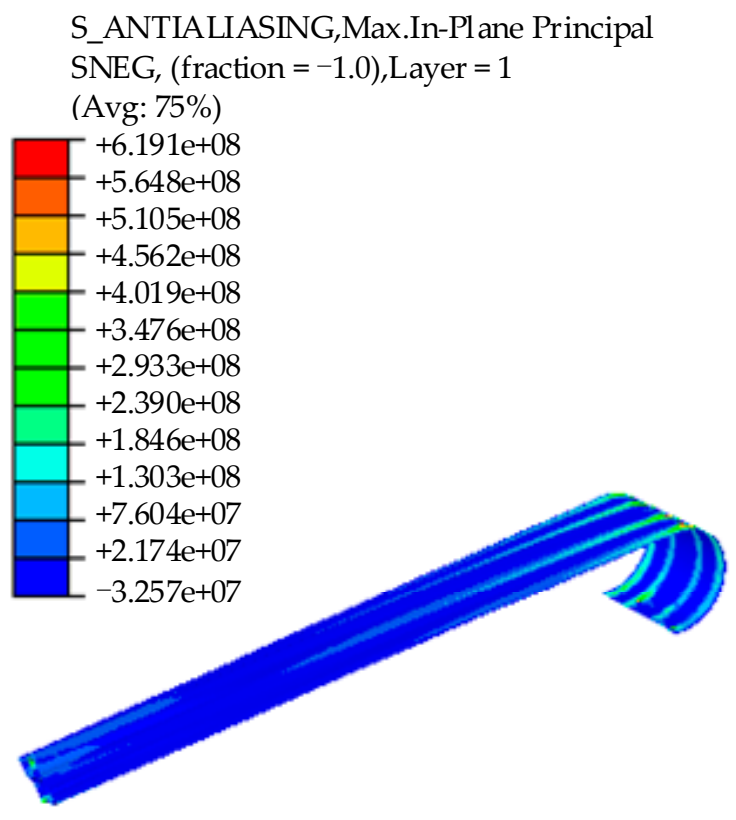

(c) $180^{\circ}$

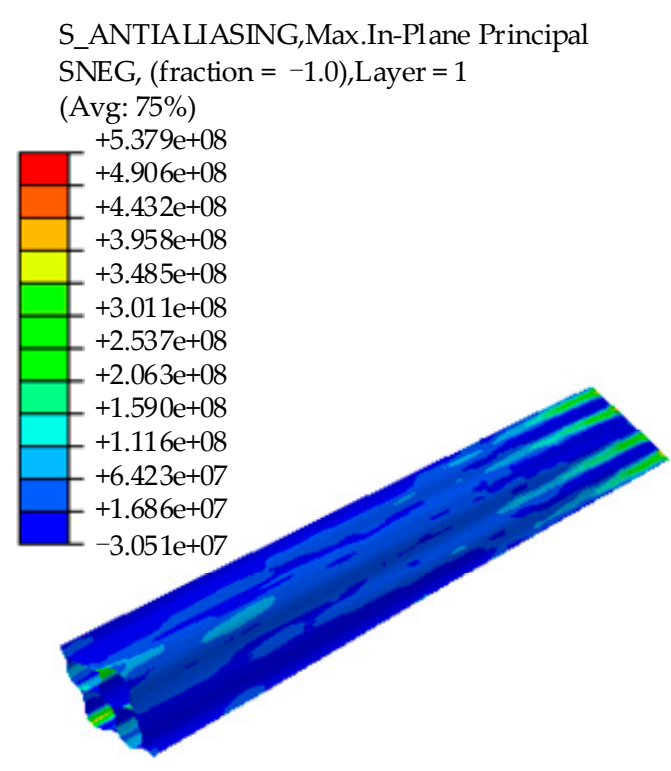

(b) holding

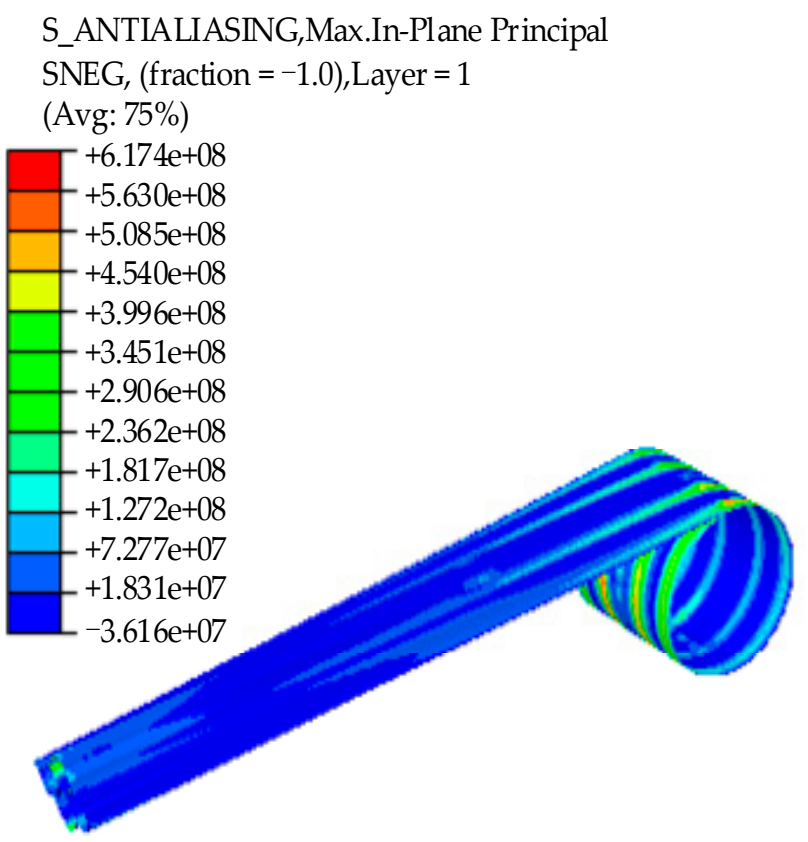

(d) $360^{\circ}$

Figure 7. Principal stress nephogram of one FLHD boom with coiling of $360^{\circ}$ (Unit: pa). 


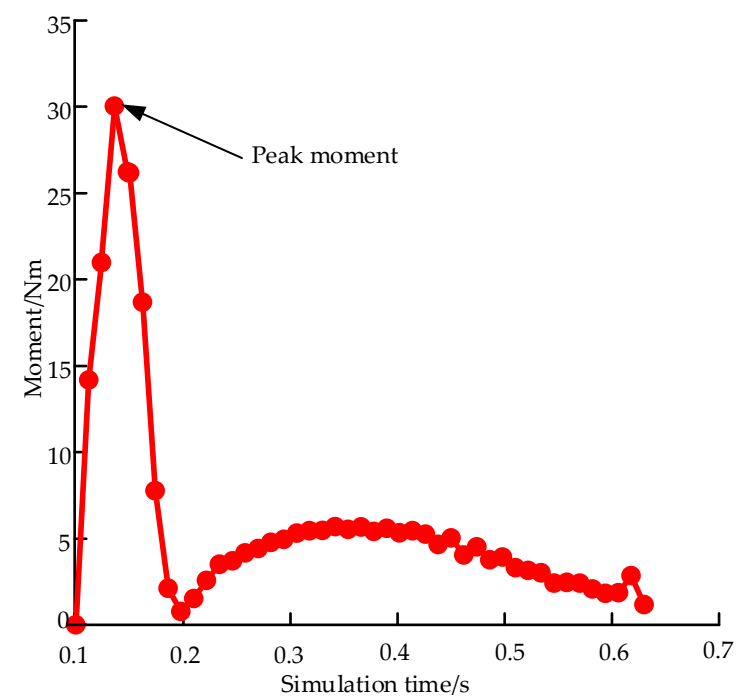

Figure 8. Moment of RP1 during the whole coiling process.

\section{BPNN Surrogate Model Method}

\subsection{Description of the Optimization Problem}

The simulation time of the FE model is too long and finding the optimal size of the FDLH boom requires a large number of model simulations. Thus, establishing a mapping relationship between variables and targets is necessary to save time and resources. Because this procedure is complex and mathematically challenging, an artificial NN is used as a surrogate model to obtain the mapping relation.

\subsection{BPNN Surrogate Model}

The BPNN surrogate model is established to represent the mapping relationship between inputs and outputs through the NN. The response value of the point to be measured is then predicted through the mapping relationship to save time and resources. The BPNN is a multilayer feed-forward NN, and the three-layer NN structure is composed of an input layer, a hidden layer, and an output layer, as shown in Figure 9. The layer to layer is fully interconnected, and no mutual connection occurs between the same layer. The $x_{1}, x_{2}$, and $x_{3}$ are the three-dimensional input vectors corresponding to the two-dimensional output vectors $y_{1}$ and $y_{2}$. The 3-15-2 structure is adopted [23], where $w_{i, j}$ represents the weight value from the $i$ th node of the hidden layer to the $j$ th node of the input layer, $\theta_{i}$ represents the threshold value of the $i$ th node of the hidden layer, $w_{k i}$ is the weight from the $k$ th node of the output layer to the $i$ th node of the hidden layer, $a_{k}$ is the threshold of the $k$ th node of the output layer, and $O_{k}$ is the output of the $k$ th node of the output layer.

The input of the $i$ th node of the hidden layer:

$$
n t_{i}=\sum_{j=1}^{M} w_{i j} x_{j}
$$

The linear function can be written as:

$$
O_{i j}=\beta\left(O_{i j}\right)=\psi\left(O_{i j}\right)=n_{e} t_{i}+\theta_{i}
$$

The sigmoid logarithm is defined as:

$$
O_{i}=\phi\left(\text { net }_{i}\right)=\frac{1}{1+e^{-n e t_{i}}}=\frac{1}{1+e^{-\left(\sum_{j=1}^{M} w_{i j} x_{j}+\theta_{i}\right)}}
$$


where $E_{p}$ is the error criterion function of each sample $p, M$ is the number of output nodes, and $T_{k}$ and $O_{k}$ are the desired and actual outputs, respectively.

$$
E_{p}=\frac{1}{2} \sum_{k=1}^{M}\left(T_{k}-O_{k}\right)^{2}
$$

Modifying the output layer weight and threshold correction $\Delta \omega_{k i}$ and $\Delta a_{k}$, hidden layer weight and threshold correction $\Delta \omega_{i j}$ and $\Delta \theta_{i}$ according to the gradient descent method of error, and $\eta$ is the learning rate.

$$
\Delta \omega_{k i}=-\eta \frac{\partial E_{p}}{\partial \omega_{k i}}, \Delta a_{k}=-\eta \frac{\partial E_{p}}{\partial a_{k}}, \Delta \omega_{i j}=-\eta \frac{\partial E_{p}}{\partial \omega_{i j}}, \Delta \theta_{i}=-\eta \frac{\partial E_{p}}{\partial \theta_{i}}
$$

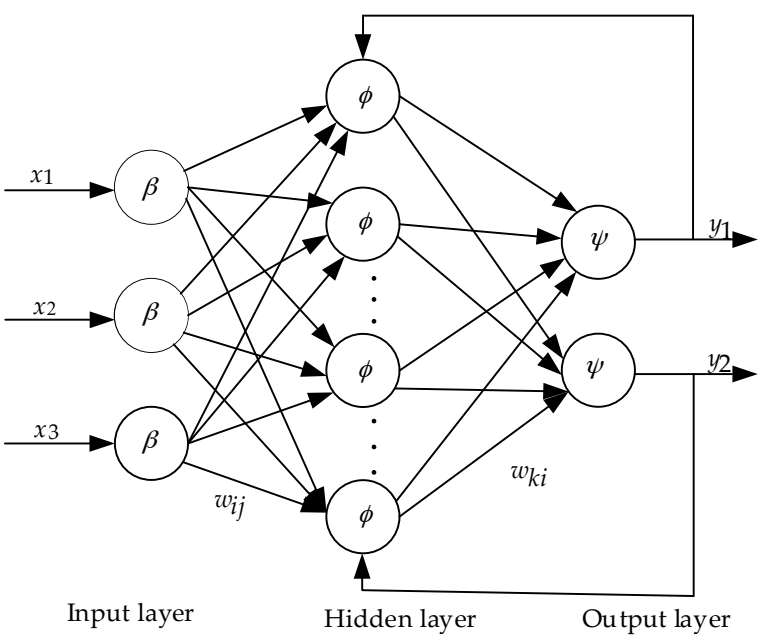

Figure 9. Simplified schematic of the BPNN structure.

\section{Build BPNN Surrogate Model of Mpeak and Smax}

\subsection{Sample Points}

There are three design variables of the FLHD boom in the sample space, i.e., $\theta, r$, and $w$, each of which varies within a specific range. The design range of all parameters is determined according to the actual situation. Considering the complexity of the running time of FE simulations, a total of 36 combinations of design sample points with different levels of the full-factor method are selected, as shown in Table 2.

\subsection{Error Analysis of the Surrogate Model}

In general, the smaller the error of the surrogate model, the greater its fit and the higher its prediction accuracy. However, in actual applications, decreases in fitting error initially decrease the prediction error but then increase the error when a certain fitting error is reached. This phenomenon is referred to as the overfitting phenomenon in the BPNN. Obtaining more data is the best way to solve this overfitting problem. If sufficient data are available, the model can identify exceptions with greater accuracy. A diagram of the fitting effect of the training sample points is shown in Figure 10. An expression of the relative error is then defined to analyze the fitting effect of the model quantitatively.

$$
R E=\frac{\widetilde{f}\left(x^{(i)}\right)-f\left(x^{(i)}\right)}{f\left(x^{(i)}\right)} \quad i=1,2, \cdots m
$$

where $f\left(x^{(i)}\right)$ is the FE result of sample $i, \widetilde{f}\left(x^{(i)}\right)$ is the BPNN surrogate model result of sample $i$, and $m$ is the number of samples. 
Table 2. Sample points.

\begin{tabular}{|c|c|c|c|c|c|}
\hline No. & $r / \mathrm{mm}$ & $\theta /^{\circ}$ & $w / \mathrm{mm}$ & $M_{\text {peak }} / \mathrm{Nm}$ & $S_{\text {max }} / \mathrm{MPa}$ \\
\hline 1 & 27 & 52.5 & 7 & 30.01 & 620 \\
\hline 2 & 27 & 52.5 & 8 & 30.02 & 632 \\
\hline 3 & 27 & 52.5 & 9 & 38.32 & 635 \\
\hline 4 & 27 & 55 & 7 & 27.81 & 632 \\
\hline 5 & 27 & 55 & 8 & 30.88 & 634 \\
\hline 6 & 27 & 55 & 9 & 33.67 & 654 \\
\hline 7 & 27 & 57.5 & 7 & 26.08 & 702 \\
\hline 8 & 27 & 57.5 & 8 & 31.79 & 713 \\
\hline 9 & 27 & 57.5 & 9 & 32.87 & 675 \\
\hline 10 & 27 & 60 & 7 & 26.44 & 620 \\
\hline 11 & 27 & 60 & 8 & 38.28 & 679 \\
\hline 12 & 27 & 60 & 9 & 34.43 & 719 \\
\hline 13 & 25 & 52.5 & 7 & 29.86 & 647 \\
\hline 14 & 25 & 52.5 & 8 & 34.94 & 685 \\
\hline 15 & 25 & 52.5 & 9 & 33.89 & 682 \\
\hline 16 & 25 & 55 & 7 & 25.58 & 663 \\
\hline 17 & 25 & 55 & 8 & 25.62 & 687 \\
\hline 18 & 25 & 55 & 9 & 29.88 & 675 \\
\hline 19 & 25 & 57.5 & 7 & 27.23 & 674 \\
\hline 20 & 25 & 57.5 & 8 & 27.91 & 671 \\
\hline 21 & 25 & 57.5 & 9 & 28.60 & 674 \\
\hline 22 & 25 & 60 & 7 & 30.03 & 656 \\
\hline 23 & 25 & 60 & 8 & 28.14 & 649 \\
\hline 24 & 25 & 60 & 9 & 31.60 & 694 \\
\hline 25 & 23 & 52.5 & 7 & 29.45 & 624 \\
\hline 26 & 23 & 52.5 & 8 & 31.18 & 620 \\
\hline 27 & 23 & 52.5 & 9 & 31.35 & 673 \\
\hline 28 & 23 & 55 & 7 & 37.76 & 704 \\
\hline 29 & 23 & 55 & 8 & 39.33 & 714 \\
\hline 30 & 23 & 55 & 9 & 28.64 & 730 \\
\hline 31 & 23 & 57.5 & 7 & 30.52 & 681 \\
\hline 32 & 23 & 57.5 & 8 & 32.62 & 695 \\
\hline 33 & 23 & 57.5 & 9 & 29.32 & 729 \\
\hline 34 & 23 & 60 & 7 & 34.57 & 642 \\
\hline 35 & 23 & 60 & 8 & 35.17 & 736 \\
\hline 36 & 23 & 60 & 9 & 41.01 & 668 \\
\hline
\end{tabular}
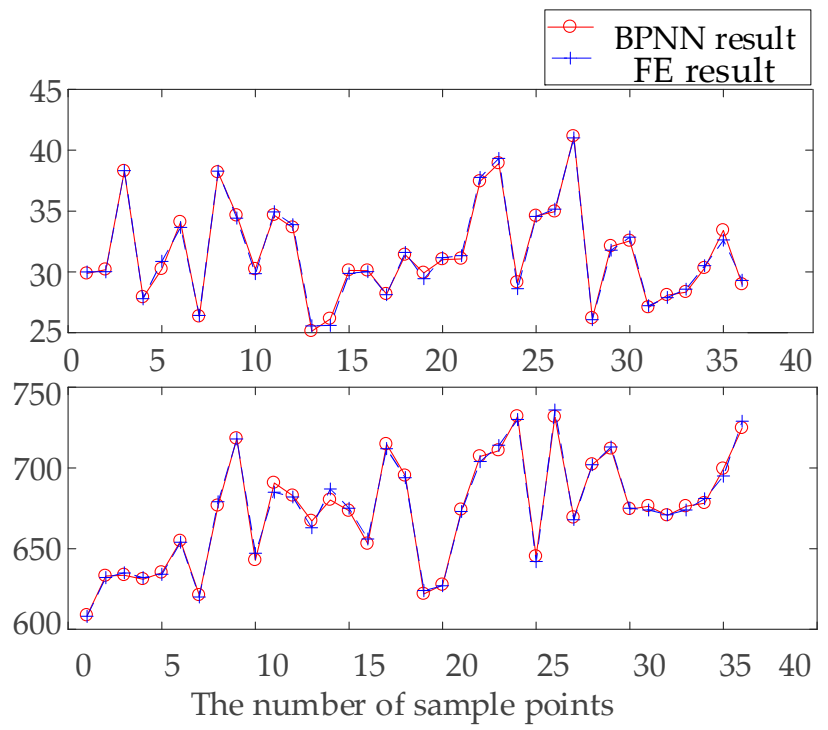

Figure 10. Fitting diagram of training sample points. 
The errors between the FE and BPNN surrogate model results of $M_{\text {peak }}$ and $S_{\text {max }}$ are shown in Figure 11. The REs of $S_{\text {max }}$ and $M_{\text {peak }}$ are approximately $\pm 3 \%$, which means the fitting precision meets the present requirements. Five samples are randomly generated in the sample space to test the model prediction accuracy of the BPNN surrogate model, and the REs of the tested sample points are shown in Table 3. The REs obtained do not exceed $-6.3 \%$, which meets the accuracy requirements of the current work.

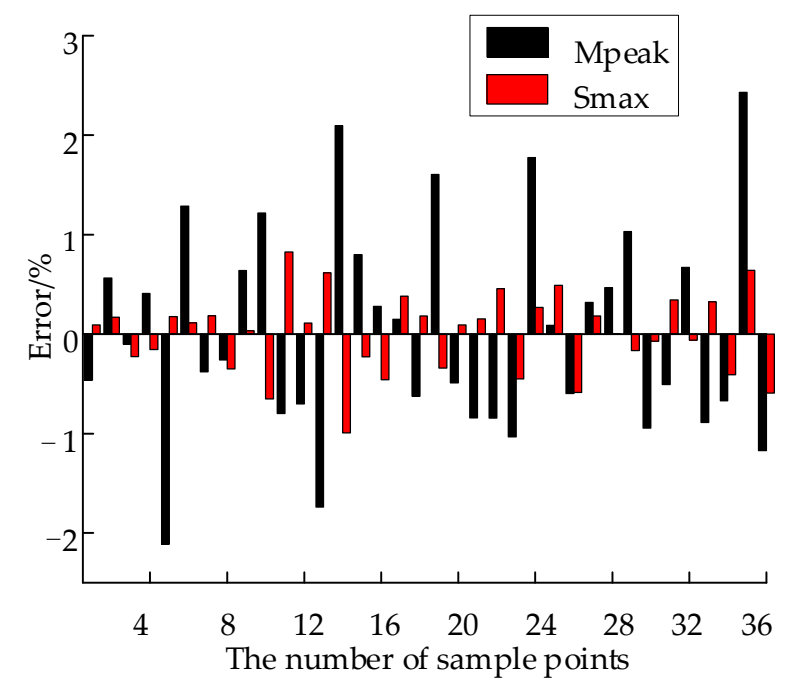

Figure 11. REs of $M_{\text {peak }}$ and $S_{\text {max }}$.

Table 3. Errors of the test sample points.

\begin{tabular}{|c|c|c|c|c|c|c|c|c|c|}
\hline \multirow[b]{2}{*}{ No } & \multirow[b]{2}{*}{$\mathrm{r} / \mathrm{mm}$} & \multirow[b]{2}{*}{$\theta /^{\circ}$} & \multirow[b]{2}{*}{$w / \mathrm{mm}$} & \multicolumn{2}{|c|}{$M_{\text {peak }} / \mathrm{Nm}$} & \multirow[b]{2}{*}{ RE/(\%) } & \multicolumn{2}{|c|}{$S_{\max } / \mathrm{MPa}$} & \multirow[b]{2}{*}{ RE/(\%) } \\
\hline & & & & $\begin{array}{c}\text { FE } \\
\text { Result }\end{array}$ & $\begin{array}{l}\text { BPNN } \\
\text { Result }\end{array}$ & & $\begin{array}{c}\text { FE } \\
\text { Result }\end{array}$ & $\begin{array}{l}\text { BPNN } \\
\text { Result }\end{array}$ & \\
\hline 1 & 23 & 57 & 8.5 & 35.089 & 32.8801 & -6.30 & 714 & 737.5714 & 3.30 \\
\hline 2 & 24 & 53 & 7.5 & 30.3478 & 29.3259 & -3.37 & 655 & 648.597 & -0.98 \\
\hline 3 & 24.5 & 56 & 7.3 & 25.534 & 26.013 & 1.88 & 643 & 677.66 & 5.39 \\
\hline 4 & 26.5 & 60 & 7.2 & 24.926 & 25.775 & 3.41 & 657 & 639.709 & -2.63 \\
\hline 5 & 25.5 & 54 & 8.5 & 30.2272 & 29.7083 & -1.72 & 667 & 691.2579 & 3.64 \\
\hline
\end{tabular}

\subsection{Response Surface}

The response surfaces of $M_{\text {peak }}$ and $S_{\text {max }}$ obtained when the $r$ values of the FLHD boom are 23, 25, and $27 \mathrm{~mm}$ are shown in Figure 12. When $r$ and $\theta$ are constant, the $M_{\text {peak }}$ first increases and then decreases while $S_{\max }$ continuously increases as $w$ increases from $7 \mathrm{~mm}$ to $9 \mathrm{~mm}$. Small changes in $M_{\text {peak }}$ and $S_{\text {max }}$ are noted as $\theta$ increases from $52^{\circ}$ to $60^{\circ}$. These results indicate that changes in $\theta$ have little effect, whereas changes in $w$ exert remarkable effects on $M_{\text {peak }}$ and $S_{\text {max }}$. The sensitivity of $M_{\text {peak }}$ and $S_{\text {max }}$ to $\theta$ is enhanced as $r$ increases. 


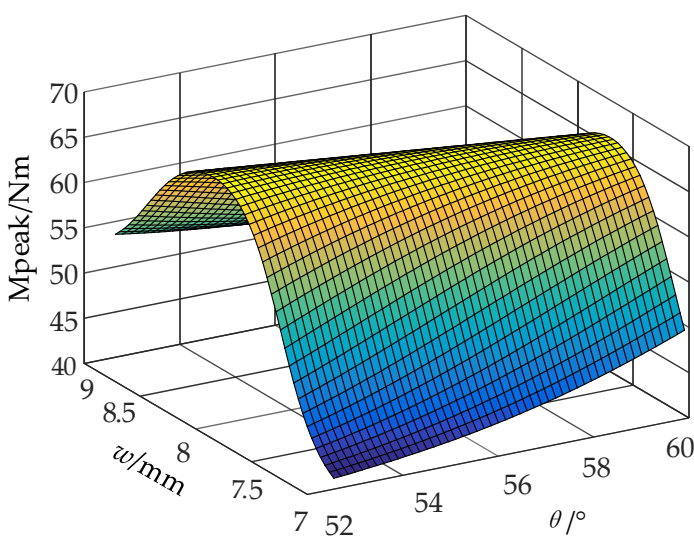

(a) RS of $M_{\text {peak }}(r=23 \mathrm{~mm})$

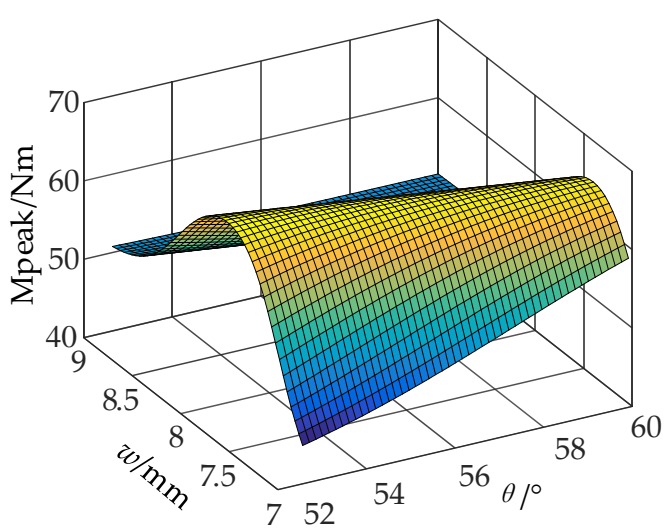

(c) RS of $M_{\text {peak }}(\mathrm{r}=25 \mathrm{~mm})$

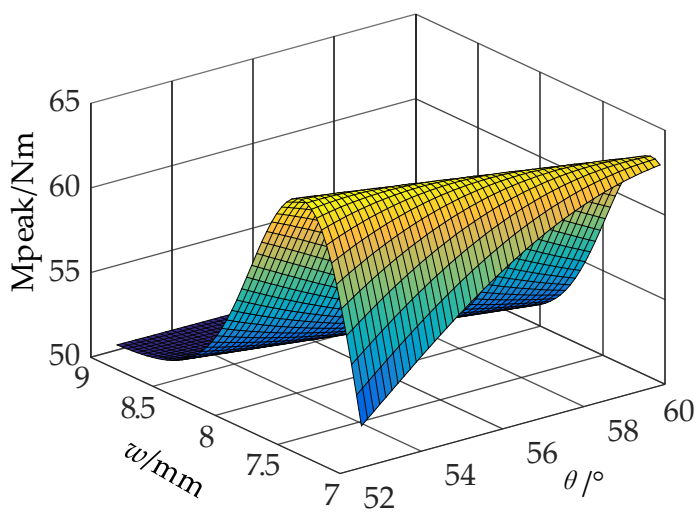

(e) RS of $M_{\text {peak }}(r=27 \mathrm{~mm})$

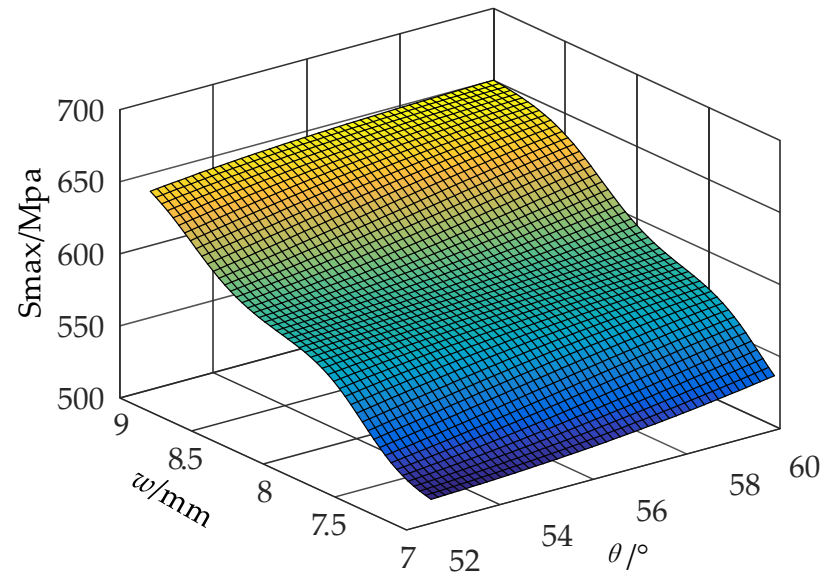

(b) RS of $S_{\max }(r=23 \mathrm{~mm})$

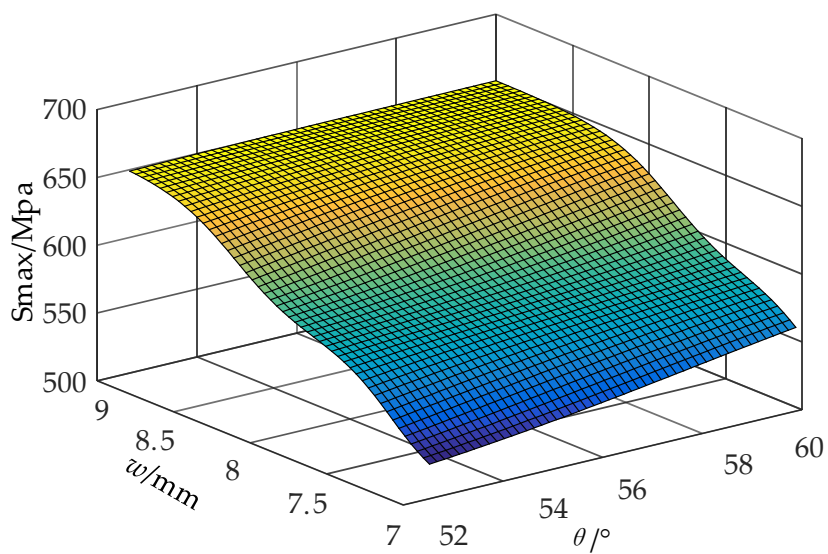

(d) RS of $S_{\max }(r=25 \mathrm{~mm})$

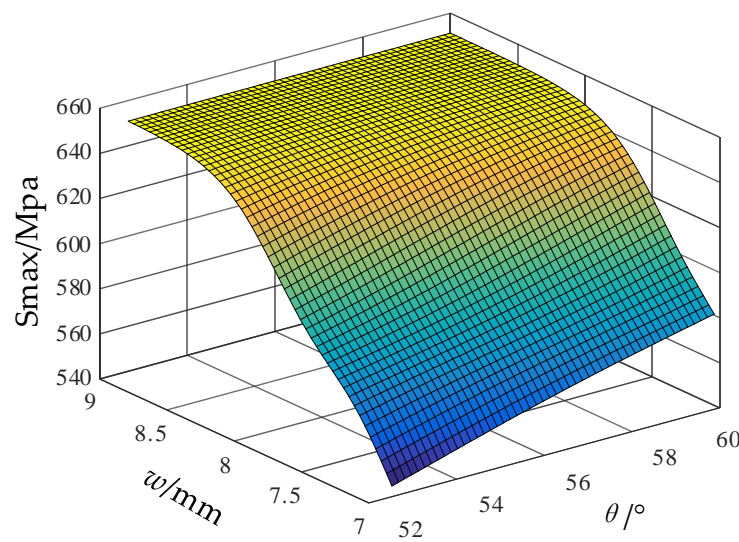

(f) RS of $S_{\max }(r=27 \mathrm{~mm})$

Figure 12. Response surfaces of the $M_{\text {peak }}$ and $S_{\max }$ under different $r$ value.

\section{Multi-Objective Optimization Design}

The coiling $M_{\text {peak }}$ of a boom represents its ability to resist external disturbances and lock deployable membrane antennas and solar and drag sails. When the maximum concentrated stress exceeds the allowable stress, the FLHD boom is destroyed. The mass of the modified boom directly affects the cost of launching spacecraft. Thus, $M_{\text {peak }}$ and mass are selected 
as objectives, and $S_{\max }$ is selected as the constraint. Moreover, $\theta, r$, and $w$ are set as design variables. The multi-objective design model of the FLHD boom can be written as follows:

$$
\left\{\begin{array}{c}
\text { Opt. }\left\{M_{f}^{p}(w, \theta) \leq 35 \mathrm{Nm}, \text { mass }\left.\right|_{\min }\right\} \\
\text { S.t. } S_{\max }(w, \theta) \leq 650 \mathrm{Mpa} \\
23 \mathrm{~mm} \leq r \leq 27 \mathrm{~mm} \\
7 \mathrm{~mm} \leq w \leq 9 \mathrm{~mm} \\
52.5^{\circ} \leq \theta \leq 60^{\circ} .
\end{array}\right.
$$

The Objective value of the objective function is calculated as the weighted sum of all optimized objective components $X_{i}$ and the weighting factor $W_{i}$ and scaling factor $S F_{i}$ corresponding to the $i$ th objective component, as shown in Equation (9).

$$
\text { Objective }=\sum \frac{W_{i} X_{i}}{S F_{i}}
$$

If the $S F_{i}$ and weight of the target component are equal, larger magnitudes of the target component will have greater impacts on the optimization result. Thus, the $S F_{i}$ and weight are set to adjust the importance of each subtarget in the optimization process. The scaling factor $S F_{i}$ is uniformly set to 1 , and the weight factors of $M_{\text {peak }}, S_{\text {max }}$, and mass are set to 1.0, 1.0, and 20, respectively, according to the order of magnitude to facilitate calculations. The Pareto fronts of mass and $M_{\text {peak }}$ in the optimization process are shown in Figure 13.

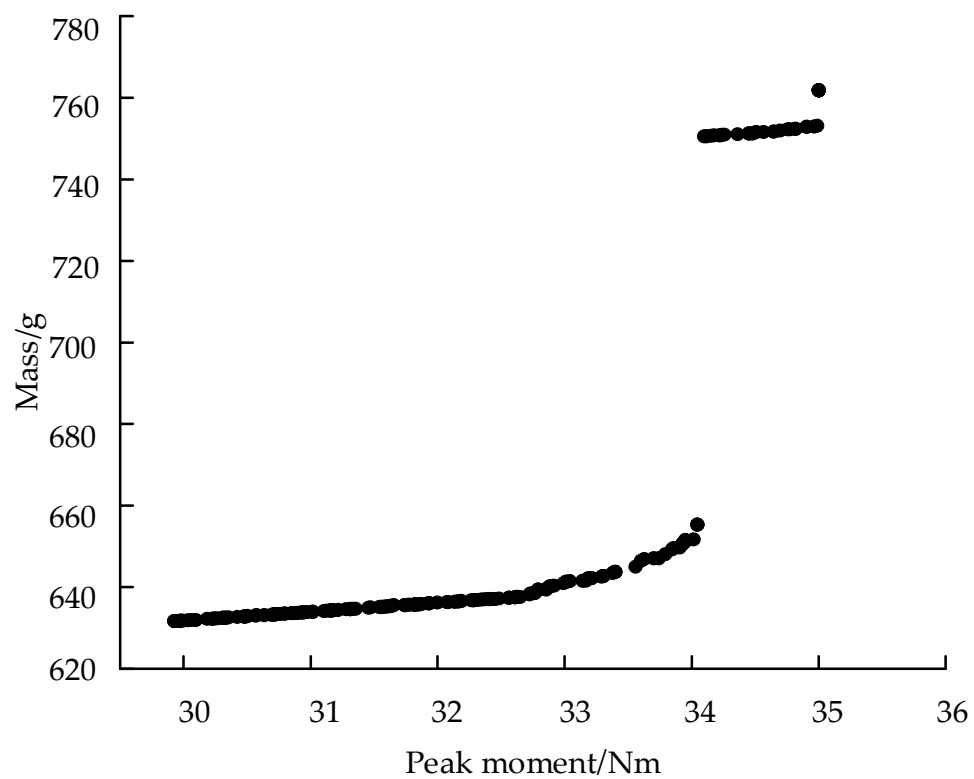

Figure 13. Pareto fronts of Mass and $M_{\text {peak }}$ for FLHD booms with $S_{\text {max }} \leq 650 \mathrm{MPa}$.

In the non-dominant sorting genetic algorithm (NSGA-II), each target parameter is processed separately. Standard genetic manipulations of mutation and hybridization perform in the design. The selection process is based on two main mechanisms: "nondominated sorting" and "congestion distance sorting." By the end of the optimization run, each design has a "best" combination of goals, and it is impossible to improve one goal without sacrificing one or more other goals. NSGA-II is used to carry out multi-objective optimization in Isight software. The optimization part of the paper establishes the BPNN surrogate model with Matlab, forms an input-output mapping relationship, and then uses the OPTIMIZATION module in Isight for algorithm iteration optimization. The whole loop is closed, and the whole process can be automated, as shown in Figure 14. Here, the maximum number of iterations is set to 50 , the population size is set to 48 , and the crossover 
probability is set to 0.9 . The optimal result is $r=23 \mathrm{~mm}, \theta=53.31^{\circ}$, and $w=7.52 \mathrm{~mm}$. The REs of $M_{\text {peak }}$ and $S_{\text {max }}$ are less than $10 \%$, as shown in Table 4.

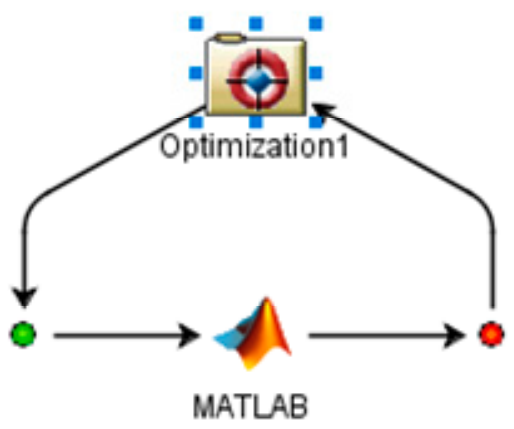

Figure 14. Optimization loop diagram.

Table 4. Optimal design of the FLHD boom.

\begin{tabular}{|c|c|c|c|c|c|c|c|c|c|}
\hline \multirow[b]{2}{*}{ No. } & \multirow[b]{2}{*}{$r / \mathrm{mm}$} & \multirow[b]{2}{*}{$\varphi /^{\circ}$} & \multirow[b]{2}{*}{$w / \mathrm{mm}$} & \multicolumn{2}{|c|}{$M_{p e a k} / \mathrm{Nm}$} & \multirow[b]{2}{*}{ RE/(\%) } & \multicolumn{2}{|c|}{$S_{\max } / \mathrm{MPa}$} & \multirow[b]{2}{*}{ RE/(\%) } \\
\hline & & & & $\begin{array}{c}\text { FE } \\
\text { Result }\end{array}$ & $\begin{array}{l}\text { BPNN } \\
\text { Result }\end{array}$ & & $\begin{array}{c}\text { FE } \\
\text { Result }\end{array}$ & $\begin{array}{l}\text { BPNN } \\
\text { Result }\end{array}$ & \\
\hline 1 & 23.00 & 53.31 & 7.52 & 33.72 & 34.02 & 0.87 & 688 & 650 & -5.54 \\
\hline
\end{tabular}

\section{Conclusions}

This paper describes the design, coiling dynamics analysis, and optimization of a new type of thin-walled boom. The conclusions are summarized as follows:

1. A novel type of FLHD boom characterized by a high spreading ratio, light weight, and simple structure is proposed.

2. A surrogate model of $M_{\text {peak }}$ and $S_{\text {max }}$ is established by BPNN, and the REs of the $M_{\text {peak }}$ and $S_{\max }$ of 36 sample points do not exceed $3 \%$, which verifies the accuracy of the surrogate model.

3. NSGA-II is used to complete the multi-objective optimization design. $M_{\text {peak }}$ and mass are selected as objectives, $S_{\max }$ is selected as the constraint, and $\theta, r$, and $w$ are set as design variables. The optimal design structure is $r=23.00 \mathrm{~mm}, \theta=53.31^{\circ}$, and $w=7.52 \mathrm{~mm}$. The REs of the optimal design results are less than $-5.54 \%$.

4. The next step is to build an experimental platform to verify the reliability of the theory and simulation analysis. After the verification results are reliable, FLHD boom will be applied to the folding of large-aperture array antennas.

Author Contributions: Finite element model, H.Y.; BPNN model method, S.F.; Optimization, Y.W. and C.S. All authors have read and agreed to the published version of the manuscript.

Funding: This work was supported in part by Anhui Province Natural Science Foundation of under grant 2108085QE221 and in part by the National Natural Science Foundation of China under grants 51975001 and 52005123.

Institutional Review Board Statement: Not applicable.

Informed Consent Statement: Not applicable.

Data Availability Statement: Not applicable.

Conflicts of Interest: The authors declare no conflict of interest. 


\section{References}

1. Hakkak, F.; Khodam, S. On calculation of preliminary design parameters for lenticular booms. Proc. IMechE Part G J. Aerosp. Eng. 2007, 221, 377-384. [CrossRef]

2. Yang, H.; Liu, L.; Guo, H.; Lu, F.; Liu, Y. Wrapping dynamic analysis and optimization of deployable composite triangular rollable and collapsible booms. Struct. Multidiscip. Optim. 2018, 59, 1371-1383. [CrossRef]

3. Yang, H.; Liu, R.; Wang, Y.; Deng, Z.; Guo, H. Experiment and multiobjective optimization design of tape-spring hinges. Struct. Multidiscip. Optim. 2015, 51, 1373-1384. [CrossRef]

4. Stabile, A.; Laurenzi, S. Coiling dynamic analysis of thin-walled composite deployable boom. Compos. Struct. 2014, 113, 429-436. [CrossRef]

5. Hoskin, A.; Viquerat, A.; Aglietti, G.S. Tip force during blossoming of coiled deployable booms. Int. J. Solids Struct. 2017, 118-119, 58-69. [CrossRef]

6. Banik, J.; Hausgen, P. Roll-out solar array (ROSA): Next generation flexible solar array technology. In Proceedings of the AIAA SPACE and Astronautics Forum and Exposition, Orlando, FL, USA, 12-14 September 2017.

7. Mallikarachchi, H.M.Y.C.; Pellegrino, S. Deployment Dynamics of Ultrathin Composite Booms with Tape-Spring Hinges. J. Spacecr. Rocket. 2014, 51, 604-613. [CrossRef]

8. Mallikarachchi, H.M.Y.C.; Pellegrino, S. Design of Ultrathin Composite Self-Deployable Booms. J. Spacecr. Rocket. 2014, 51, 1811-1821. [CrossRef]

9. Mallikarachchi, H. Predicting mechanical properties of thin woven carbon fiber reinforced laminates. Thin-Walled Struct. 2019, 135, 297-305. [CrossRef]

10. Chu, Z.; Lei, Y. Design theory and dynamic analysis of a deployable boom. Mech. Mach. Theory 2014, 71, 126-141. [CrossRef]

11. Chu, Z.; Lei, Y.; Li, D. Dynamics and robust adaptive control of a deployable boom for a space probe. Acta Astronaut. 2014, 97, 138-150. [CrossRef]

12. Cai, J.G.; Zhou, Y.; Wang, X.Y.; Xu, Y.X.; Feng, J. Dynamic analysis of a cylindrical boom based on Miura Origami. Steel Compos. Struct. 2018, 28, 607-615.

13. Bai, J.-B.; Chen, D.; Xiong, J.-J.; Shenoi, R.A. Folding analysis for thin-walled deployable composite boom. Acta Astronaut. 2019, 159, 622-636. [CrossRef]

14. Angeletti, F.; Gasbarri, P.; Sabatini, M. Optimal design and robust analysis of a net of active devices for micro-vibration control of an on-orbit large space antenna. Acta Astronaut. 2019, 164, 241-253. [CrossRef]

15. Chen, W.; Fang, G.; Hu, Y. An experimental and numerical study of flattening and wrapping process of deployable composite thin-walled lenticular tubes. Thin-Walled Struct. 2017, 111, 38-47. [CrossRef]

16. Li, C.; Angeles, J.; Guo, H.; Tang, D.; Liu, R.; Qin, Z.; Xiao, H. On the Actuation Modes of a Multiloop Mechanism for Space Applications. IEEE/ASME Trans. Mechatron. 2021. [CrossRef]

17. Liu, J.; Wen, G.; Zuo, H.Z.; Qing, Q. A simple reliability-based topology optimization approach for continuum structures using a topology description function. Eng. Optim. 2016, 48, 1182-1201. [CrossRef]

18. Bessa, M.; Pellegrino, S. Design of ultra-thin shell structures in the stochastic post-buckling range using Bayesian machine learning and optimization. Int. J. Solids Struct. 2018, 139-140, 174-188. [CrossRef]

19. Bessa, M.A.; Bostanabad, R.; Liu, Z.; Hu, A.; Apley, D.W.; Brinson, C.; Chen, W.; Liu, W.K. A framework for data-driven analysis of materials under uncertainty: Countering the curse of dimensionality. Comput. Methods Appl. Mech. Eng. 2017, 320, 633-667. [CrossRef]

20. Seffen, K.; Wang, B.; Guest, S. Folded orthotropic tape-springs. J. Mech. Phys. Solids 2018, 123, 138-148. [CrossRef]

21. Roybal, F.; Banik, J.; Murphey, T. Development of an Elastically Deployable Boom for Tensioned Planar Structures. In Proceedings of the 48th AIAA/ASME/ASCE/AHS/ASC Structures, Structural Dynamics, and Materials Conference, Honolulu, HI, USA, 23-26 April 2007.

22. Yang, H.; Lu, F.S.; Guo, H.W.; Liu, R.Q. Design of a new N-shape composite ultra-thin deployable boom in the post-buckling range using response surface method and optimization. IEEE Access 2019, 7, 129659-129665. [CrossRef]

23. Jiang, Z.; Gu, M. Optimization of a fender structure for the crashworthiness design. Mater. Des. 2010, 31, 1085-1095. [CrossRef] 